\title{
Socio-demographic Characteristics of Depressive Illness Patients Attending a Selected Military Hospital
}

\author{
Hamid MA ${ }^{1}$, Rahman $\mathrm{MM}^{2}$, Islam MR ${ }^{3}$, Islam SS4 \\ DOI: https:/ / doi.org/ 10.3329/ jafmc.v15i2.50829
}

\begin{abstract}
Introduction: Depressive illness is generally not perceived as an important public health problem and is not priority in health care delivery system in Bangladesh. It is the leading cause of diseaserelated disability in the country today. Gender differences in depression are likely to be result of certain risk factors.
\end{abstract}

Objectives: To find out gender difference in epidemiological and socio-demographic features associated with depressive illness.

Materials and Methods: This descriptive cross sectional study was carried out among 91 diagnosed depressive patients attending in the psychiatry department of CMH Dhaka from January to December 2014. The patients were interviewed through an intervieweradministered questionnaire. Data were analyzed by using SPSS version 20. Chi-square test was used to see the level of significance.

Results: In this study the mean age of the patients was $34.47 \pm 9.577$ years. The study revealed that depressive illness appears to be more in female during child bearing and child rearing period of 1639 years and male of $40-63$ years were more sufferer than female which was significantly different $(p<0.05)$. In this study $63.74 \%$ of patients were female and $36.26 \%$ were male with ratio of $1.757: 1$. It was observed that the association of depression with residence in urban area in female $(72.1 \%)$ was significantly $(p<0.05)$ higher than male $(27.9 \%)$ in the same area. This study revealed that the association of depression with history of financial hardship in female was statistically significant $(p<0.05)$ over their male counter-part. The study also revealed that strenuous job was significantly $(p<0.05)$ associated with depression in female than male.

Conclusion: The overall finding of the study indicates that possibility of gender difference in certain epidemiological and sociodemographic features of depressive illness is significantly present. As depressive illness has significant impact on burden of disease and quality of life, this issue needs to be addressed.

Key-words: Depressive illness, Gender difference, Epidemiological and Socio-demographic features.

\section{Introduction}

The global burden of mental disorders reveals depression as being a significant and growing public health problem associated with a heavy burden of morbidity and disability in both developed and developing nations ${ }^{1}$. In Bangladesh, depressive illness is also an important public health problem and one of the key issues of concern'2. In our country, the life-time prevalence of depressive illness is $4.6 \%$ and male-female ratio is $1: 2$. Due to adverse social circumstances the incidence of depression is more common in females ${ }^{3}$. Depression can be the result of many factors. The determinants of depressive illness have been conceptualized to have a number of interacting social components like sociodemographic and economic characteristics ${ }^{4}$. Many people are unable to withstand the set point for usual change of life and are overwhelmed by depression; as a result, symptoms of depression may develop ${ }^{1}$. Gender is one of the critical determinants of health which influences the socioeconomic position, roles, rank and social status, access to resources and treatment in a society. As such, gender is important in defining susceptibility and exposure to a number of mental health risks 5 . Gender difference of depressive illness occurs due to different and unequal distribution of sociodemographic, economic and social factors between men and women. Sometimes gender roles lead to inequality ${ }^{6}$. The gender difference in depression appears to be greatest during the childbearing and child-rearing years of young to mid adulthood, the period in women's lives when unequal socio-economic status, pressure from social roles and interpersonal conflicts are likely to have their greatest impact?. Depression in divorced and separated women are significantly higher than men.

The burden of depressive illness place on individuals, their families and the public health system makes the identification of at risk groups an important area of research?. The study on "Gender Difference in Epidemiological and Socio-demographic Features of Depressive Illness" was undertaken to find out who is most at risk of experiencing depression as well as the risk factor associated with them. The finding of this study may provide some guide-lines in taking preventing measures and to make further specific study. To reduce the contribution of gender in the rise of prevalence of depression among patient population, gender sensitive health care is essential and services must be customized to meet the needs of each gender.

\section{Materials and Methods}

This descriptive cross sectional study was conducted to find out gender difference in epidemiological and sociodemographic features of depressive illness among ninety one diagnosed depressive patients who were treated in the psychiatry department of CMH Dhaka from January to December 2014. Depressive patients who were willing to participate were included in this study irrespective of their age. Non-probability sampling of convenient type was followed to select the patients. The data were collected with an interviewer-administered questionnaire by face to face interview. All data were checked thoroughly after collection. Data processing and analysis were done by using SPSS version 20 . For inferential statistics Chi-square test was done to see the level of significance and $p<0.05$ was considered to be significant. 


\section{Results}

Distribution of the patients by age group found majority (41.76\%) of them were in age group of 30-39 years, $27.47 \%$ were from 20-29 years and $23.08 \%$ were from $40-49$ years age group. Rest of the patients were $<20$ years $(3.30 \%)$ and $\geq 50$ years $(4.40 \%)$ age group (Figure-1). The mean age of the patients was $34.47 \pm 9.577$ years. The age of the patients ranged between 16 and 63 years. Among 91 patients $66(72.5 \%)$ were less than 40 years of age group and $25(27.5 \%)$ were more than 40 years of age group. Female $(71.2 \%)$ were more than male $(28.8 \%)$ which was significantly different $(p<0.05)$. Out of 91 patients $61(67 \%)$ were from urban area and
$30(33 \%)$ were from rural area. Within urban area female $(72.1 \%)$ were more than male $(27.9 \%)$ which was significantly different $(p<$ 0.05). Among 91 patients 54(58\%) of them had history of financial hardship and $37(42 \%)$ patients had no such history of financial hardship. Out of 54 exposed patients female (55.6\%) were more than male $(44.4 \%)$ which was significantly different $(p<0.05)$. Distribution of sex of the patients by strenuous job, where it was found that out of 91 patients 64 of them had history of strenuous job. It was also found that within history of strenuous job female (70.3\%) were more than male (29.7\%) which was significantly different $(\mathrm{p}<0.05)($ Table-l).

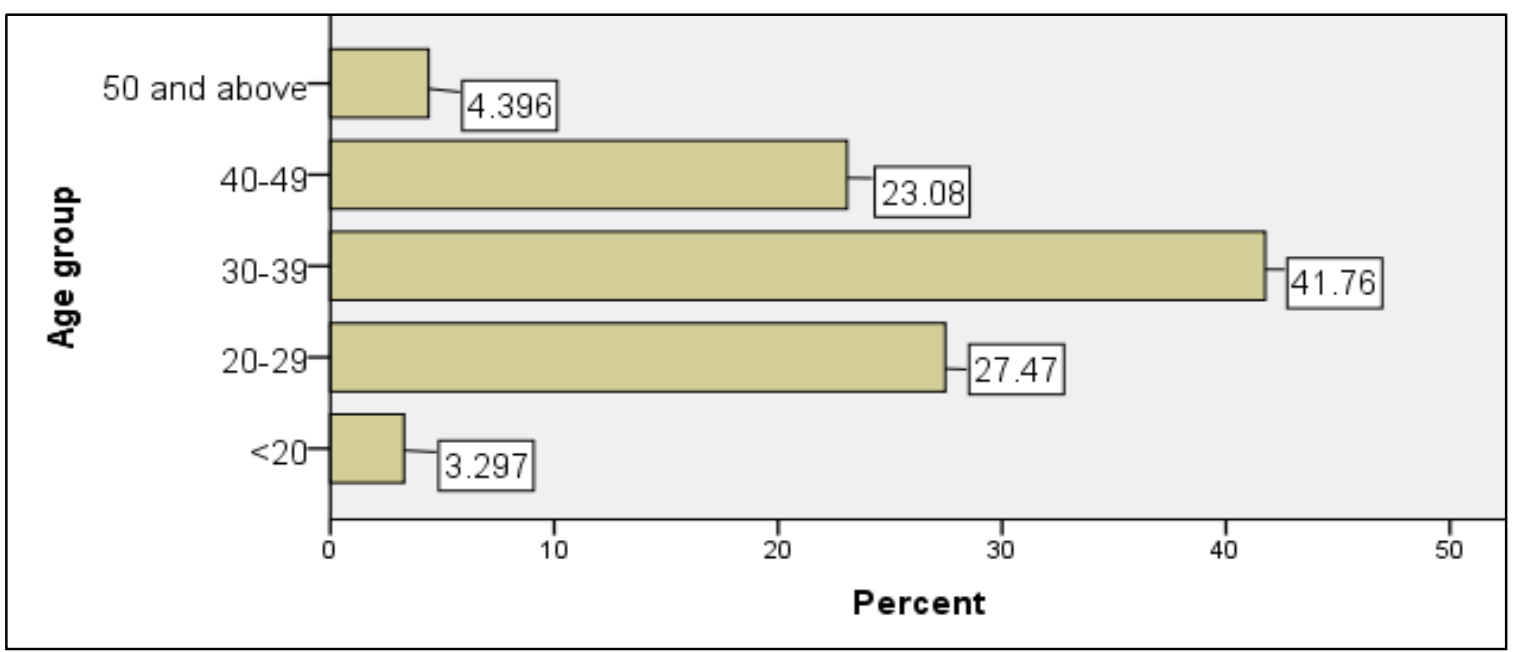

Figure-1: Distribution of the patients by age group $(n=91)$

Table -I: Distribution of patients by sex with age group, place of residence, history of financial hardship and history of strenuous job ( $\mathrm{n}=91$ )

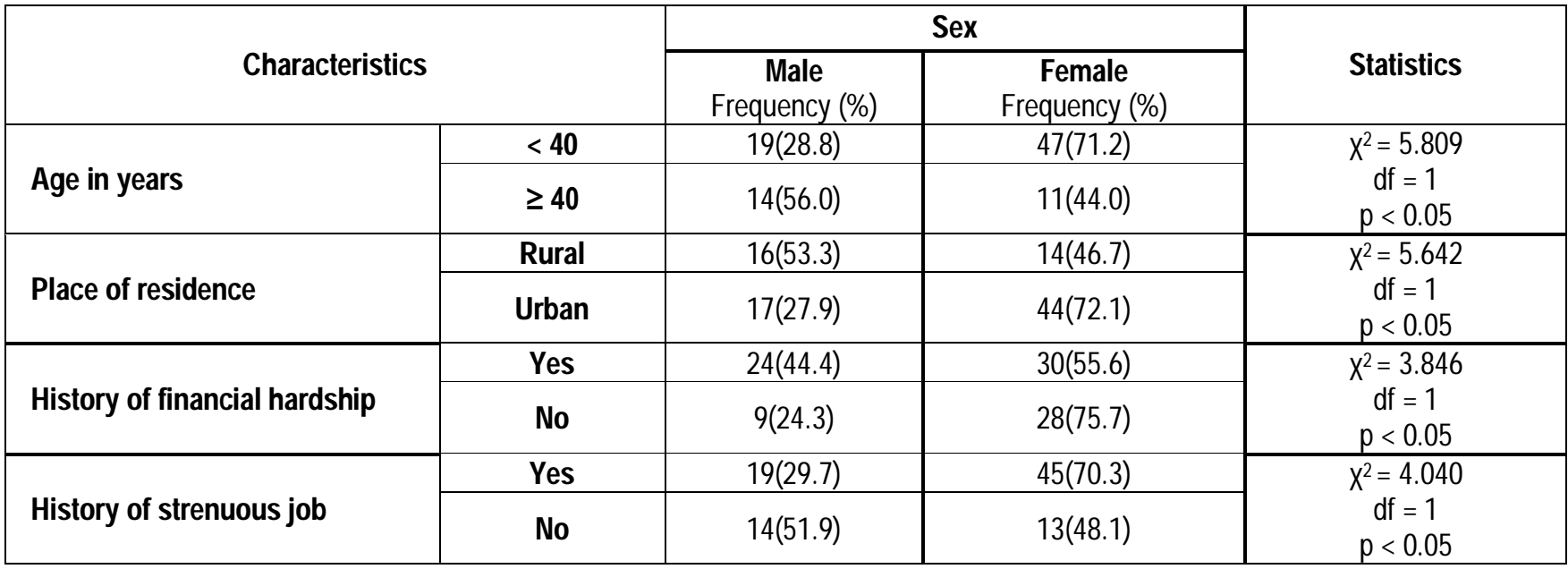

\section{Discussion}

The prevalence, incidence and morbidity risk of depressive illness are higher in female than male ${ }^{9}$. Gender difference in depression is often preceded by certain social and demographic risk factors and economic determinants ${ }^{7}$. In this study the mean age of the patient was $34.47 \pm 9.577$ years with range of $16-63$ years which were nearer to the mean age (40 years) and range of age (20-50 years) of the study conducted by Sadock et al10. Majority (41.76\%) of patients were within 30-39 years of age group followed by $27.47 \%$ in $20-29$ years of age group. This result is consistent with the study result of Choudhury and Rahman ${ }^{11}$ conducted in 2004. It was observed that young and mid-aged (16-39 years) female were more (51.6\%) sufferers than male (20.9\%); on the other hand, male of $\geq 40$ years were more (15.4\%) sufferers than female (12.1\%) and positive association found with age group and sex for depression. It was found that male was prone to develop depressive illness at $\geq 40$ years and female were likely to develop depressive illness at $<40$ years. So, the study revealed that gender difference in depression appears to be more in female during the child-bearing and childrearing years of young to mid adulthood probably due to unequal socio-economic status and pressure from social role and interpersonal conflict. This age patterns with gender are highly significant $(p<0.05)$ for association with depression, this result is 
consistent with study of Leach ${ }^{7}$ in 2009, Sadock et al10 in 2007 and Al-Farooq and Ray'2 in 2011.

Majority (63.74\%) of the patients was female and $36.26 \%$ were male. Female and male ratio was 1.76:1. So, depression found relatively more among the female than their male counter-part. It was found consistent with the result of a study conducted by Choudhury and Rahman ${ }^{11}$ in 2004 . Other studies conducted by Leach in 2009, Warner et al13 in 2007 and Angold et al ${ }^{14}$ in 1998 also revealed the same that depression was much higher in women than in men. It was found that among 91 patients majority $(67 \%)$ were from urban area and $33 \%$ of them were from rural area. In this study it was revealed that prevalence of depressive illness in female of urban dwellers was significantly higher than male. This result is consistent with the study result of Hakim ${ }^{15}$ conducted in 1999. It was observed that female (72.1\%) of urban area was significantly $(p<0.05)$ associated with depression than their male $(27.9 \%)$ counter-part. Female living urban area is a trigger of depression in female over male probably due to decreased support and increased work load for women.

It was observed that out of 91 patients majority (58\%) had history of financial hardship and $42 \%$ of them had no such history of financial hardship. It was found that within history of financial hardship $44.4 \%$ were male and $56.6 \%$ were female. The association of financial hardship with depression in female was significantly $(p<0.05)$ higher than their male counter-part. This result is consistent with the study result of Nolen ${ }^{16}$ which had been carried out in 2001. It was found that among 91 patients majority (70.33\%) had history of strenuous job in their day to day activities and $40.66 \%$ of them were not exposed to strenuous job. It was observed that out of 91 patients 64 of them had history of strenuous job. It was also observed that within history of strenuous job female (70.3\%) were more than male $(29.7 \%)$ which was significantly different $(p<0.05)$. Chi-square test revealed that strenuous job was significantly $(p<0.05)$ associated with depression in female than male. The study conducted by Nolen in 2001 also found the similar finding where it was shown that women's reaction to strenuous job was more than male ${ }^{16}$.

\section{Conclusion}

The result of this study reflects that women's depressive response is higher than men's when both sexes are exposed to certain sociodemographic risk factors and economic determinants like age, place of residence, financial hardship and strenuous job. Women's higher reactivity compared with men's likely to attribute gender differences in depressive illness. High rates of depression in women invite tremendous costs in quality of life and productivity, for women themselves and their families. Understanding the gender difference in depression is important to provide gender sensitive health care to alleviate or cope up with problem. In order to address existing disparities, we need to achieve the highest possible level of health for all people. This study intends to generate some statistical information which can serve as baseline data for further in-depth study in broader perspective.

\section{References}

1. World Health Organization. (2003). Investing in Mental Health, 2003:09. https://apps.who.int/iris/ bitstream/ handle/ 10665/ 42823/ 9241562579.pdf

2. Fahmida A, Wahab MA and Rahman MM. Pattern of psychiatric morbidity among the patients admitted in a private psychiatric clinic. Bang J Med Science 2009; 8(1-2): 23-8.

3. Mohit MA, Maruf MM, Ahmed $\mathrm{H}$ et al. Depression and Physical Illnesses: An Update. BMJ 2011; 40(1):53-8.

4. Rosenquis J, Fowler JH and Christakis NA. Social network determinants of depression. Harvard Medical School Journal 2010; 6:273-81.

5. World Health Organization. Gender Disparities in Mental Health. Department of Mental Health and substances Misuse 2011:1-5.

6. Chegg Study. Gender Socialization. Available at https://www. chegg.com/homework-help/definitions/gender-socialization-49.

7. Leach LS, Christensen H, Mackinnon AJ et al. Gender differences in depression and anxiety across the adult life span. Social Psychiatry 2008; 43(12):983-98.

8. Katzir NM. Gender differences in the association between Depression and physical activity. San Diego State University J, USA, 2012:1.

9. Piccinelli $M$ and Wilkinson G. Gender differences in Depressive illness: Critical Review. BJP 2000; 177:486-92.

10. Sadock BJ and Sadock VA. Kaplan \& Sadock's Synopsis of Psychiatry. Behavioral Sciences/Clinical Psychiatry 2007:527-45.

11. Choudhury AU and Rahman MH. Evaluation of somatic symptoms in depression and perception regarding treatment. BAFMJ 2004; 33(1): 53-5.

12. Al-Farooq SA and Ray NC. Psychiatric Morbidity: Diagnoses of the Patients attending Psychiatry Outpatient Department of a Hospital. Bang Development Studies, 29 Sep 2011.

13. Warner $\mathrm{CM}$, Warner $\mathrm{CH}$, Breitbach $\mathrm{J}$ et al. Depression in entrylevel military personnel. Mil Med J 2007; 172(8):795-799

14. Angold A, Costello EJ and Worthman CM. Puberty and depression: the role of age, pubertal status and pubertal timing. Cambridge Journal Psychological Medicine 1998; 28(1):51-61.

15. Hakim M. Socio-demographic and economic characteristics of mentally ill patients admitted in different hospital of Dhaka city. Armed Forces Medical Institute 1999:39-68.

16. Nolen S-Hoeksema. Gender Differences in Depression. Blackwell Publishers Inc 2001; 10:3-11.-9. 